\title{
Presentación del Tema Central \\ Migración forzada, desarraigo y despojo: itinerancia obligada, una ciudadanía inconclusa
}

\section{Presentation of Central Theme: Forced migration, uprooting and dispossession: forced itinerancy, unfinished citizenship}

\author{
Myriam Ocampo Prado \\ Universidad Javeriana, Bogotá, Colombia \\ ORCID: https://orcid.org/0000-0002-1817-6798 \\ ISSN: ISSN-OI85-4259; e- ISSN: 2007-9I76
} DoI: http://dx.doi.org/IO.28928/ri/7620I4/ptc/ocampopradom

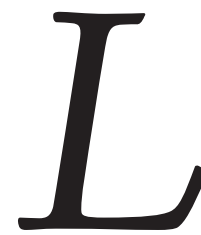

AS MIGRACIONES SIEMPRE HAN ESTADO PRESENTES en la historia de la humanidad. Desde los orígenes de nuestros ancestros en otros continentes, las comunidades de humanos eran nómadas que se movilizaban impulsados por la búsqueda de alimentos para subsistir. Inicialmente, se movían dentro de lo que hoy conocemos como el continente africano, para después viajar hacia los demás, comenzando por Asia, Europa y finalmente poblar América y Oceanía. Este carácter migratorio de las primeras tribus humanas fue lo que permitió a nuestra especie no solo sobrevivir, sino expandirse y poblar todos los lugares de nuestro planeta. 
Las investigaciones sobre el tema muestran movimientos migratorios dentro de África, siguiendo a las manadas de animales que también se desplazaban de acuerdo con los cambios del clima. El homo sapiens entonces debe su supervivencia como especie al aspecto migratorio de sus orígenes, entre otras cosas porque así podían protegerse mejor de los depredadores que los acechaban. Cuando el clima fue propicio, nuestros ancestros migraron hacia la región euroasiática, y poblaron luego los demás continentes. Las migraciones hacia el suelo americano se produjeron hace unos miles de años, aunque todavía existen varias hipótesis sobre la especificación de los lugares por los que ingresaron hace unos 30000 años. Nuestros antepasados modernos ya habitaban regiones tan distantes como Australia, Europa, Sudáfrica o Siberia. Varios trabajos de investigación publicados en 2007 aportaron datos sobre la fecha en la que podrían haber salido de África algunos grupos y han reconstruido parte de ese largo periplo (Novo, 20II).

Con posterioridad al desarrollo de la agricultura, los seres humanos se asentaron y fueron formando territorios, configurando sistemas culturales dentro de las tribus que originaron los primeros asentamientos urbanos y creando las primeras grandes civilizaciones en las riberas de gigantescos ríos. Por ello, son conocidas como civilizaciones fluviales. Este es el caso de la región de Mesopotamia asiática, ubicada entre los ríos Tigris y Éufrates, que albergó a los sumerios y a los babilonios. Otra civilización fluvial fue la egipcia, que se conformó en relación con el río Nilo, o las civilizaciones en la India, desarrolladas en las márgenes del Ganges, o la China alrededor del río Amarillo. Las grandes civilizaciones fluviales, cuya economía se basaba en los cultivos de regadío y cuya base humana era una población numerosa y en gran parte urbanizada, nacieron en las llanuras aluviales, producto de los arrastres de los ríos (Turri, 1983).

En la medida en que estas civilizaciones se fueron desarrollando comenzaron a aniquilar y desplazar a las tribus cercanas; de esta manera fueron expandiéndose por amplios territorios, y así se fue generando la migración forzada de múltiples tribus que se vieron obligadas a volver al nomadismo para evitar la esclavitud por parte de sus invasores, hasta encontrar otra vez lugares donde sembrar. Tal vez el caso más emblemático y recordado históricamente es el de los hebreos, que fueron desplazados sucesivamente por varias civilizaciones.

Con el advenimiento del imperio romano se empezó a practicar sistemáticamente la creación de colonias permanentes con el fin de gobernar y explotar los recursos de los territorios colonizados, lo que implicaba la esclavitud de los habitantes originarios y la migración de las poblaciones sometidas hacia los bordes del imperio, donde se veían obligados a restablecerse, resistiendo las continuas persecuciones por parte 
de los ejércitos romanos que siempre estaban en contienda con las comunidades desplazadas por su imperio. La creación sistemática de colonias fue una de las claves para que el imperio romano consolidara su dominio por tan largo tiempo, en tan vastos territorios.

El método romano de colonización, como una forma de explotar los recursos de los territorios invadidos, fue reproducido por el imperio español en América. La instalación de colonias implicó la migración masiva de españoles, en su mayoría aventureros y militares que llegaron al denominado nuevo continente en búsqueda de riquezas. La colonización española en América no fue un movimiento migratorio libre ni una partida de personas, familias y grupos de individuos con miras a la fundación de una nueva patria. Tampoco fue una emigración forzada, impuesta desde las instancias del poder político. Todas las decisiones individuales de emigrar, e incluso las de trasladarse por un tiempo a los territorios de ultramar, requerían para su realización un permiso estatal. La colonización española de América constituyó un ejemplo de política metropolitana de emigración y población fijada por ley (Palma, 1996).

Entre las consecuencias de la colonización española en América se halla el aniquilamiento de grandes contingentes de población indígena, caídos durante la invasión, y aquellos sobrevivientes que no fueron esclavizados se vieron obligados a desplazarse hacia las periferias de sus antiguos asentamientos, en la medida en que los colonizadores iban avanzando. Los indígenas, sublevados frente a sus invasores, protagonizaron luchas cruentas. Las batallas libradas fueron incontables, porque en tierras americanas había innumerables tribus; de ese modo, la violencia fue el instrumento más utilizado en esta conquista. Comenzó a practicarse el genocidio, luego continuó con la explotación inhumana de los socavones de las minas, de donde extraían minerales. Allí, los indígenas sufrían el desarraigo al ser obligados a dejar sus tierras y a sus familias, y se les imponía un ritmo de trabajo aniquilante. Los socavones les devoraban los pulmones y los dejaban rápidamente discapacitados (Veksler, 2006).

Desde la invasión española en América, la población indígena se vio obligada constantemente a migrar debido a las exigencias de los colonizadores por conseguir el oro y la plata americanos. La explotación de estos metales contribuyó a formar los primeros grandes capitales europeos, que dinamizaron la economía y detonaron la Revolución Industrial (Veksler, 2006). En la actualidad continúan presentándose situaciones semejantes: las comunidades indígenas se siguen viendo desplazadas por la explotación de los recursos naturales, ahora por parte de empresas multinacionales del comercio y la extracción de metales. 
La estructura social de América Latina en la actualidad reproduce ciertos patrones heredados de la Colonia. Los descendientes de los colonizadores españoles conformaron elites minoritarias locales que controlaban los medios y modos de producción de sus países acumulando grandes capitales, hecho histórico que contrasta con la pobreza de la mayoría de la población mestiza, indígena, mulata y negra que ha vivido sometida a diferentes formas de exclusión. Después de cinco siglos, muchos grupos de estos pobladores que no han logrado la integración y la movilidad social ascendente dentro de las estructuras sociales estratificadas continúan conformando cinturones de miseria en las grandes ciudades. Con elevada frecuencia estas personas son desplazados internos forzados por distintas formas de violencia presentes en las sociedades de América Latina a establecerse en las periferias urbanas. Actualmente, según los datos de la CEPAL, América Latina y el Caribe continúa siendo la región más desigual del mundo en términos de la distribución de ingresos y de activos como la tierra, el capital financiero, la tecnología, y debido a la elevada proporción de personas que continúa marginada de la oferta de salud y educación de calidad (CEPAL, 2OII).

La migración por violencia es un fenómeno que se ha manifestado en la mayoría de los países latinoamericanos a lo largo de su historia. En las últimas décadas del siglo veinte y en lo que llevamos de este, el fenómeno migratorio forzado aumentó. La desigualdad, la pobreza, los conflictos armados, el narcotráfico, han incrementado la migración forzada de millones de latinoamericanos que se ven obligados a huir de sus lugares para escapar de estas problemáticas que amenazan sus vidas y vulneran sus derechos humanos.

Los problemas generados por la desigualdad social produjeron conflictos políticos violentos. La concentración de la riqueza en las capas dominantes, los movimientos sociales en reclamo de cambios en las estructuras sociales, participación e inclusión como actores políticos y mejora en las condiciones de vida, han sido el germen de situaciones bélicas y cruentas guerras, sobre todo en Centroamérica y Colombia. El conocido informe Sanford (1989) señala que en el contexto de las crisis de pobreza, violencia política y confrontación armada, más de dos millones de centroamericanos abandonaron sus localidades y países de origen en aras de salvar sus vidas, proteger su libertad y salvaguardar su persona, familia y comunidad. Se trató de una migración masiva originada por la violencia (Salvadó, 1992).

Las guerras en Centroamérica en las décadas de los ochenta y noventa fueron la causa del desplazamiento de millones de personas que se vieron obligadas a establecerse en los centros urbanos de sus países. Allí la protección estatal era mínima y asimismo su situación de precariedad como migrantes aumentaba en las periferias, 
donde eran ubicados en campamentos. Los desplazados que transitaban a países fronterizos eran igualmente puestos en campamentos para refugiados. Esta política de "puertas abiertas" o de protección ofrecida, interna o externamente, reveló la trágica violación de los derechos de los migrantes forzados, quienes no alcanzaban a encontrar posibilidades de salvaguardar su vida en condiciones adecuadas a su dignidad como personas.

Es evidente en el caso centroamericano que la situación de desigualdad social heredada desde la Colonia fue el detonante de una serie de guerras que produjeron la muerte y la migración forzada de campesinos hacia las ciudades. Otras poblaciones se trasladaron hacia los demás países de la región, y al hacerlo perdieron su ciudadanía y quedaron en condiciones de marginalidad extrema.

La situación en Colombia es semejante a la vivida en Centroamérica, la confrontación y las condiciones creadas como correlato de un conflicto armado que lleva más de 60 años sin solución genera migraciones forzadas recurrentes. El desarraigo y la desterritorialización de millones de personas impulsan a diversos grupos sociales a vivir hacinados en la miseria de los inquilinatos de las periferias en las principales ciudades del país. Sus lazos ancestrales han sido desdibujados. Constituyen grupos en permanente recomposición como comunidades. El índice de desigualdad aumenta dramáticamente debido a su procedencia rural. Como campesinos asediados por actores armados tuvieron que migrar hacia las ciudades, donde su ciudadanía se resquebrajó, tanto por los hechos que minaron su capacidad de proveerse un bienestar, como por las limitaciones del Estado para restituir efectivamente sus derechos vulnerados.

Específicamente en Colombia, que en el contexto mundial y en el de países en conflicto armado es el que presenta el mayor número de desplazados internos, la pobreza de la población campesina es uno de los detonantes de la confrontación. Esta situación está relacionada directamente con el acaparamiento de la mayoría de las tierras cultivables por un pequeño grupo de terratenientes que tradicionalmente las han usufructuado (Osorio, 2014). Colombia es uno de los países de América Latina que nunca pudo realizar una reforma agraria, desde el siglo diecinueve cualquier intento de reforma fue impedido mediante las armas, por parte de las clases dominantes que causaron constantes guerras civiles. Esta concentración de la tierra no ha sido atendida por el Estado a lo largo de la historia. Los campesinos sin tierra son utilizados como mano de obra mal remunerada y por ende mal alimentada, y el Estado no ha podido revertir esta circunstacia debido a la cooptación del poder político local y nacional en manos de los latifundistas. 
Tradicionalmente las guerras en Colombia han estado asociadas directamente con el problema de la tierra, lo cual constituye un acumulado histórico que naturaliza la desigualdad (Dorado, 2014). El actual conflicto en Colombia ha agravado esta situación; el desplazamiento forzado ha evidenciado una contrarreforma agraria implantada mediante una estrategia paramilitar de despojo a poblaciones campesinas, con recursos del narcotráfico, que aumentó el acaparamiento de las tierras en manos de las minorías que ya poseían la mayoría de las tierras (Orozco, 2007). Si bien el actual gobierno ha puesto en marcha la ley 1448 de 2011 , conocida como Ley de víctimas y restitución de tierras en Colombia, las acciones dentro de este marco han debido ganarle terreno a una constante oposición política y armada de grupos que quieren evitar el proceso de restitución de tierras a los campesinos desplazados.

En Colombia, en los últimos 30 años, el combustible de la guerra fue el ingreso de dinero procedente del narcotráfico, que incrementó la violencia, debido al aumento del arsenal de los bandos involucrados en el conflicto. La aceptación por las elites de fondos de origen incierto implicó la creación de estructuras paramilitares y organizaciones criminales de narcotraficantes, para frenar el avance de las guerrillas en los campos y las ciudades. Los grupos guerrilleros también aceptaron el comercio y el dinero del narcotráfico para incrementar su armamento. Con el incremento de la violencia en el contexto del conflicto armado aumentó dramáticamente el desplazamiento hasta convertir Colombia en el país con más desplazados internos del mundo, cifra que asciende a más de cuatro millones de personas según un informe de la ACNUR (2OI3).

Si la situación del desplazamiento forzado en Colombia se relaciona con la violencia generada por las condiciones que mantienen el conflicto político armado, enmarcándolo en una compleja trama de lucha de clases, centralismo y al mismo tiempo debilidad del Estado para controlar el territorio y regular los intereses desmesurados de grupos de poder, así como una cultura política conservadora y proclive a sostener los privilegios de grupos hegemónicos, y la influencia desestabilizadora del narcotráfico en términos económicos, políticos, sociales y culturales, en México la migración forzada es causada por las organizaciones criminales, narcotraficantes que se disputan el control del territorio para el tráfico de estupefacientes. A su vez, estas organizaciones libran una guerra contra el Estado federal por continuar con sus actividades ilícitas. El desplazamiento interno forzado - DIf- en México, al que nos referimos en este análisis, es un efecto colateral de un complejo sistema de violencia ejercida contra la población civil, no vinculada al crimen organizado, y como un intento por escapar -al menos parcialmente- del ejercicio efectivo de dicha violencia, tal como lo plantea en su artículo Luz María Salazar. 
La violencia y la presencia amenazante del narcotráfico hacen que todos los habitantes en territorios por donde cruzan las rutas del comercio ilegal se vean afectadas por las disputas entre los miembros de los cárteles, que ejercen un poder coercitivo sobre la población para evitar que los rivales se infiltren en la región controlada. La cruenta guerra deriva continuamente en masacres que aterrorizan a los pobladores locales, quienes se ven obligados a migrar para proteger sus vidas. Así, el desplazamiento forzado es un recurso de supervivencia de las poblaciones civiles no vinculadas a los cárteles. El DIF se constituye en acción y reacción en situaciones extremas que evidencian la incapacidad de las instituciones públicas para garantizar la vida, como muestra Luz María Salazar en este tema central.

Estos habitantes desplazados por la violencia se ven obligados a abandonar los territorios en los que construyeron sus vidas; muchas veces pierden los bienes que habían conseguido con años de trabajo; ven abruptamente cómo todos los lazos de arraigo a su comunidad son destruidos. El cambio es tan dramático que se ven obligados a vivir en grandes ciudades en medio de la miseria, con sus derechos vulnerados y con pocas posibilidades de verlos restablecidos con prontitud porque el Estado no cuenta con herramientas efectivas para hacerlo. La población desplazada es asistida por instancias oficiales en las modalidades de "albergue","ayuda" y "atención inmediata”, que son insuficientes porque no se pueden instrumentar apoyos permanentes ni monitoreados, ya que los programas oficiales son focalizados y, además, el desplazado es institucionalmente inexistente. Todo ello es analizado en el artículo de Luz María Salazar.

Las personas obligadas a migrar dentro de su propio territorio nacional pierden su lugar de residencia, su ámbito productivo, su red de relaciones sociales. Entre estas pérdidas múltiples también se cuenta la de su relación con sus territorios, les es arrebatado su referente fundante de la definición de su identidad personal y social. Los migrantes forzados, obligados a instalarse en lugares frecuentemente muy diferentes a los de su origen y a construir rápidamente, y en condiciones precarias, una relación con el territorio al que llegan, tratan de resolver su necesidad de supervivencia dentro de una situación de itinerancia y movilidad, que trastoca por completo sus vidas. De ese modo, los mayores viven el desarraigo con añoranza y dolor, mientras que las nuevas generaciones procuran constituirse un lugar para sí y navegar a través de diversas formas de precariedad.

En este sentido, la migración como problemática social revela la importancia que tiene la dimensión territorial para la condición humana; el territorio como lugar de la existencia, suma de todos los lugares concretos con los cuales el individuo se ha involucrado a lo largo del tiempo, como señala Jérôme Monnet (1999): en el 
pasado (las experiencias pasadas movilizadas por la memoria), el presente (acción y experiencia directa) y en el futuro (proyectos, anticipaciones y expectativas).

La migración forzada como cambio de lugar de residencia, ciudad o país, implica una transformación violenta y radical en la relación del sujeto con el territorio. Esta relación de territorialidad expresa una forma de "estar en el mundo". Al respecto recordamos las palabras de Rogério Haesbaert (20II) cuando afirma que cada uno de nosotros necesita territorializarse en un sentido múltiple y relacional. La desterritorialización se convierte así en proceso de ruptura de la relación con el territorio habitado, y es una ruptura instigada por la violencia. La desterritorialización se va convirtiendo en la deconstrucción de la relación con el lugar de origen, desde la pérdida de la vivienda y el domicilio fijo hasta el sentido y los significados atribuidos a los lugares habitados y recorridos. La migración forzada, como evento infortunado, genera una ruptura con esta territorialidad pasada.

Para el caso colombiano, el desplazamiento forzado sumerge a los pobladores rurales en una nueva relación con las instituciones formales. En los territorios de origen, la precaria presencia institucional no permitía a los pobladores identificar un Estado legítimo que garantizara el acceso a derechos y ejercicio de la ciudadanía plena, pues eran los grupos armados los referentes del poder político. En su nueva situación desterritorializada, el estatus de desplazado los ha involucrado en el reconocimiento de sus derechos como ciudadanos por ser víctimas del conflicto, a través de los programas asistenciales del Estado. Su existencia se ha vuelto vulnerable (Le Blanc, 2007), y ello los sitúa al mismo tiempo fuera del ejercicio libre y autónomo de la ciudadanía. Por ello, viven una suerte de "ciudadanía inconclusa", una situación en la cual las personas desplazadas forzadamente entran en un marco de relaciones de dependencia con el Estado, donde el acceso a los derechos ciudadanos (trabajo, salud, educación, vivienda, etc.) se corresponde con una vida precaria, la que sobrellevan en la ciudad donde deben remitirse al rebusque ${ }^{1}$ como única forma de acceso a recursos para la supervivencia. Este expresa la fuerza adaptativa con la que cuentan los desplazados forzados para no sucumbir ante las inclemencias de la exclusión social en la ciudad; esta precariedad caracteriza un proceso inconcluso como ciudadanos. Los estándares dentro de los cuales se piensan los ciudadanos plenos se enmarcan principalmente en una formalidad que integre todos los ámbitos de la vida social (económicos, sociales, culturales, políticos, etc.). Ello no es lo

1 El Diccionario de la Lengua Española de la RAE (20I2) define la palabra rebuscar como: 'Buscar con afán y sacrificio la solución de un problema'. 
que caracteriza la existencia de los desplazados, quienes se vinculan al nuevo entorno desde un débil sentimiento de pertenencia.

Los desplazados carecen de una inserción en la formalidad y del ejercicio de la ciudadanía, no solo por la imposibilidad del acceso pleno a los derechos, sino también por la falta de acceso al cumplimento de obligaciones dentro de una sociedad que les permita participar, sentir pertenencia a una comunidad (Kymlicka y Norman, 1996). En este orden de ideas se puede afirmar que los desplazados no están insertos dentro de una estructura democrática. La exclusión social que viven en la ciudad, el clientelismo del que son objeto, la corrupción y la burocratización que dominan en los programas asistenciales que les atañen, inciden para que la ciudadanía sea un proyecto inacabado, inconcluso, del cual ellos logran dar cuenta parcialmente, pues solo saben que tienen límites en el acceso a esos derechos ciudadanos.

Un análisis estructural del fenómeno del desplazamiento forzado muestra a los migrantes ejerciendo una ciudadanía instrumental que los despolitiza como sujetos de derechos. La vulneración los ha debilitado en su condición de seres humanos. La dependencia del asistencialismo los limita en cuanto a la construcción de su capacidad de decidir y poner en evidencia su poder como actor social. La dependencia de los auxilios estatales pone de manifiesto el daño producido a las poblaciones, tanto como las implicaciones en los nuevos modos de vida y de organización social que van reproduciendo subjetividades maltratadas, entreveradas en la lógica de una suerte de banalización del daño por parte de la sociedad, pero también mostrando las formas de resistencia del agente afectado. El fenómeno del desplazamiento forzado muestra con evidencias el alcance destructor sobre el sentimiento de comunidad.

El trabajo de Flor Edilma Osorio, "Más allá de las migraciones internas: destierro y despojo en medio de la guerra, la acumulación y el desastre" relaciona la migración forzada con la

sobreexplotación justificada en el desarrollo y el ejercicio de la violencia dos polos articulados entre los cuales oscilan y se mezclan modalidades derivadas de conflictos armados, desastres ambientales, obras de infraestructura y megaproyectos minero-energéticos, que si bien generan dinámicas específicas, están profundamente entrecruzadas e insertas en condiciones estructurales precarias, que dificultan de manera importante su resolución y el hallazgo de una respuesta integral y oportuna. Sus impactos prolongados contribuyen al empobrecimiento ampliado e inercial de las poblaciones. 
Estas relaciones esquematizadas muestran los actores en confrontación que utilizan a los pobladores como escudo para sus acciones bélicas, y convierten a las personas en objetivo militar, las despojan de sus bienes, en la guerra mercantil y económica en la cual los grandes propietarios cuentan con la tierra de los pobladores para desplegar actividades productivas a escala o para explotar los minerales del subsuelo. Lo político queda supeditado al usufructo y la obtención de ganancias provenientes de macroproyectos ejecutados por multinacionales.

La movilización forzada se inserta también como una de las herramientas de acción de los grupos de narcotraficantes que expulsan a los pobladores para apropiarse de sus bienes, entre ellos la tierra, como forma de expansión de sus territorios de influencia que les permitan desarrollar sus proyectos. Los desplazados por los grupos armados en diversos estados del territorio nacional mexicano muestran el fenómeno dislocador de la vida personal, social y cultural en niveles insospechados.

Luz María Salazar, en su texto "Modalidades del desplazamiento interno forzado en México" plantea un análisis de este fenómeno social -DIF- en México, y destaca tres modalidades del desplazamiento: individual, familiar y colectivo, cuya diferenciación ayuda a comprender la trascendencia y magnitud del problema en la población afectada. A partir de relatos de los desplazados y del seguimiento sistemático de registros de información con difusión nacional, Salazar analiza los desplazamientos internos de población en los diferentes estados del país durante el periodo 2007-2012.

El texto de Philippe Chenut y Myriam Ocampo, titulado"Reasentamiento tras el desplazamiento forzado: dos comunidades étnicas en Colombia", da cuenta del acontecer de los desplazados para asentarse y reconstruir su vida dentro de lo que se ha llamado el proceso de restablecimiento cuando se ven forzados a iniciar el difícil camino de itinerancias y desplazamientos sucesivos por el territorio nacional. El proceso de restablecimiento a partir de la reubicación en un lugar como personas desplazadas, pertenecientes a grupos étnicos, reviste un interés particular en este texto. A diferencia de otros grupos de desplazados, como pueden ser los campesinos, la territorialidad en la que estaban inmersos antes del desplazamiento se caracteriza por un conjunto de elementos asociados a su manera particular de ver el mundo, basada en tradiciones ancestrales. La reterritorialización de dos comunidades distintas: afrocolombianos del Medio Atrato en el Pacífico, reasentados en la localidad bogotana de Suba, y campesinos-indígenas de la etnia Nasa, reubicados en el municipio de Timbío, dentro del Departamento del Cauca, suroccidente del país, ha indicado que los niveles de subsistencia y la capacidad de generar ingresos en el nuevo territorio siguen siendo precarios en ambos casos, aun después de varios años 
de iniciado el restablecimiento. Los residentes en los territorios de reasentamiento ven de manera ambigua la llegada de los desplazados. Solidaridad, desconfianza y tensiones producidas por la aplicación diferencial de políticas públicas asistencialistas que benefician a los desplazados y limitan parcialmente a los residentes, generan interacciones complejas y dificultades de relación entre las dos comunidades.

Para las comunidades desplazadas por la violencia, transformar sus condiciones de vida para reconstruir un territorio para sí mismos constituye la esperanza de encontrar relaciones cercanas, forjar amistades honestas, solidaridades auténticas, escribir su historia como un relato significativo. En realidad, los lazos más cercanos siguen soportando el peso de las pérdidas, lo que ha ido conformando un tejido que impide el daño irreversible sobre la condición humana como portadora de ilusiones y fantasías. El compromiso con estas relaciones, consigo mismo y con los otros los hace mantenerse en el presente.

Brisa Varela aborda este asunto en su colaboración, por medio del caso de la migración de mujeres armenias en Argentina. Su investigación hace el seguimiento de tres generaciones involucradas en el desplazamiento forzado de mujeres y niñas que sufrieron las acciones de violación de los derechos humanos en contextos de violencia extrema. La autora muestra que aquellas mujeres que no vivieron los episodios de violencia de manera directa, de igual forma reciben su impronta a través de procesos de transmisión inter y transgeneracional. Su trabajo propone reflexiones sobre la problematización de los efectos materiales y psíquicos de la diáspora armenia, la relación con el espacio "de origen" cargada de memoria y emocionalidad, la identidad que remite a la invocación de los antepasados, a la delimitación de un territorio identitario y a la reivindicación por parte del grupo, del ejercicio del poder sobre este espacio idealizado. Así, a través de relatos del pasado que afectó a las primeras generaciones de mujeres migrantes y el pasado cercano, continúan teniendo la fuerza de contar y reproducir la experiencia del sufrimiento y de la supervivencia. Estas experiencias aportan potencia a la vida. La memoria de lo que se trae da sentido a la vida que ha sido dañada por los hechos de violencia.

La vida en la ciudad ubica a las víctimas de la migración forzada en una situación de desposesión que ha creado un nuevo estado de cosas. Se establece lo que puede denominarse una metamorfosis de sentido: la ciudad sitúa, ya no despoja como lo hizo la violencia rural sino que fija la desposesión en la precarización de la vida como pobre. Desterritorialización como campesino-reterritorialización como nuevo habitante en la periferia, en la margen de lo que hace urbana la vida. Todo ello integra la experiencia cotidiana del desplazado. 
La desterritorialización, esa pérdida del territorio a causa del despojo ejercido por grupos violentos, se hace real cuando se pierde la posibilidad y la capacidad de volver a construir un vínculo fundamental entre saberes y raíces, entre palabras y territorios rurales. Sanar el daño es construir un territorio para "la humanidad que somos", así de singular, única y propia, porque no hay humanidad sin territorialización, valores, sentires, prácticas. El territorio pasa de ser una generalidad como superficie de dominio a convertirse en un derecho: es el derecho a construirlo en espacio propio, en espacio que dé cuenta y referencia de lo que se es. Por ello la exigencia de los desplazados debe ser la de poder constituirse en actores con nombre propio y no víctimas de la historia.

En la sociedad urbana el despojado, el desplazado del poder que administraba en su lugar de origen o de procedencia, parece encontrarse en el ámbito de la administración de la vida entera con unos poderes externos. Dependiendo de ese poder, sin embargo, se manifiesta la potencia fundamental o la voluntad inagotable de dar forma a la vida, tomando distancia del acto opresor que lo ha forzado a la nuda vida (Agamben, 1999). ${ }^{2}$

El encuentro de relaciones-potencia para los desplazados es el contar en la memoria con la huella de "los nombres propios", de los "territorios fundamentales", de los vínculos perdidos entre saberes y raíces, palabras y territorios. El encuentro de los "desterritorializados" que caminan no ya hacia los acuerdos soberanos que propuso el Estado hobbesiano, como sometimiento a la imposición de poderes externos, sino al encuentro hacia los "nombres propios", hacia la autoafirmación que les permita reterritorializarse.

\section{Bibliografía}

Agamben, Giorgio

I999 Homo sacer: el poder soberano y la nuda vida, Pre-Textos, Valencia. Banco Mundial

2013 "Indice de Gini". Banco Mundial:

2 Nuda vida es la expresión que retoma Agamben para referirse a la vida a la que cualquiera puede dar muerte, aunque ella misma es insacrificable. Se trata de una oscura figura del derecho romano arcaico, en que la vida humana se incluye en el orden jurídico únicamente bajo la forma de su exclusión; no la soberanía, sino los códigos del poder político, revelan el arcaísmo de disponer de la vida del otro. 
http://datos.bancomundial.org/indicador/sI.POV.GINI

Debarbieux, Bernard

2003 "El territorio como recurso material", en Jacques Lévy y Michel Lussault (dir.), Dictionnaire de la géographie et de l'espace des sociétés, Belín, París.

Dorado, F.

2014 “La Guerra Civil en Colombia (II)", en el sitio América Latina en movimiento, Agencia Latinoamericana de Información (ALAI). $<$ http://alainet.org/active/73358> [consultado en 20I4]

Fondo de Población de las Naciones Unidas $2013<$ http://www.unfpa.org.co/\#\&paneli-1> [consultado en 2013] Haesbaert, Rogério

20II El mito de la desterritorialización: del fin de los territorios a la multiterritorialidad, Siglo xxi, México.

Jaramillo, Samuel y Luis Cuervo

1993 Urbanización latinoamericana: nuevas perspectivas, Escala, Bogotá.

Kymlicka, W. y Norman, W.

1996 Ciudadanía. El debate contemporáneo, Paidós, Barcelona-Buenos AiresMéxico.

Le Blanc, G.

2007 Vidas ordinarias, vidas precarias. Sobre la exclusión social, Nueva Visión, Buenos Aires.

Méndez, L.

2011 “Colombia. Pobreza e inequidad, ¿̇estructural? ¡circunstancial?”, en el sitio Desde abajo.

<http://www.desdeabajo.info/ediciones/item/17674- colombia-pobreza-e-inequidad-\% $\mathrm{C}_{2} \% \mathrm{BFestructural?.} \mathrm{html>} \mathrm{[consultado} \mathrm{en} \mathrm{20I4]}$

Mercier, M.

2009 "Una teoría del lugar", en J. W. Montoya (ed.), Lecturas en teoría de la geografía (pp. 2I-40), Universidad Nacional de Colombia, Bogotá.

Monnet, Jerome

1999 "Las escalas de la representación y el manejo del territorio", en Beatriz Nates (comp.), Territorio y cultura. Del campo a la ciudad: últimas tendencias en teoría y método. Memorias del primer seminario internacional sobre territorio y cultura, Manizales, Colombia, ABYA-YALA, Quito.

Montañez, G. y Delgado, O. 
1998 "Espacio, territorio y regiónः conceptos básicos para un proyecto nacional", en Cuadernos de Geografía, vir, (I-2), I20-I34. Universidad Nacional de Colombia, Bogotá. <http://acoge200o.homestead.com/files/ Montanez_y_Delgado._1998.pdf>

Naciones Unidas

2005 Objetivos de Desarrollo del Milenio. Una mirada desde América Latina y el Caribe. Santiago de Chile, cepal.

Novo, Javier

20II La larga marcha del homo sapiens, RBA, Barcelona.

Orozco, D. E.

2007 "La contrarreforma agraria en marcha", en sitio Agencia de Prensa Rural: $<$ http://prensarural.org/spip/spip.php?article59o> [consultado en 2014]

Palma, L. C.

1996 Emigración y colonización española en América, Universidad de los Lagos, Santiago de Chile.

Salvadó, L.

1992 La migración por violencia en Centroamérica, 1980-1990, Instituto Interamericano de Derechos Humanos, Costa Rica.

Sanford, V.

1989 La migración por violencia en Centroamérica, 1980-1990, Instituto Interamericano de Derechos Humanos, San José, Costa Rica.

Turri, E.

I983 "Los ríos y el curso de la historia", El Correo de la Unesco, septiembre I983, pp. 4-7.

Veksler, B.

2006 Una visión crítica de la conquista de América, Universidad Nacional de Entre Ríos, Buenos Aires. 